
Jo

\title{
Fibrous Monolithic Ceramics: II, Flexural Strength and Fracture Behavior of the Silicon Carbide/Graphite System
}

\author{
Suresh Baskaran* and John W. Halloran* \\ Department of Materials Science and Engineering, University of Michigan, \\ Ann Arbor, Michigan $\quad 48109$
}

\begin{abstract}
The fibrous monolith microstructure consists of high aspect ratio polycrystalline cells of $\mathrm{SiC}$ separated by thin cell boundaries containing graphite. The $\mathrm{SiC} / 100 \%$ graphite fibrous monolith has noncatastrophic fracture behavior, is damage tolerant, and is notch insensitive. The failure process is characterized by fracture along weak graphite cell boundaries. The room-temperature flexural strength is 300-350 MPa. The estimated shear strength along the graphite cell boundaries is $\approx 15 \mathrm{MPa}$. Increasing the strength of the cell boundary by additions of $\mathrm{SiC}(40-60$ vol\%) results in a monolithic $\mathrm{SiC}$ material showing brittle fracture behavior but retaining damage tolerance. Strength and fracture behavior are also influenced by cell texture and orientation.
\end{abstract}

\section{Introduction}

S IGNIFICANT improvements in the mechanical properties of ceramic materials are obtained by microstructural design that promotes interactions of cracks with various microstructural features. Ceramics with duplex compositions have been shown to be flaw tolerant with $R$-curve behavior.' Laminar structures have been designed with useful characteristics like high work-of-fracture and graceful failure. ${ }^{2,3}$ These microstructural designs and others can be created within a ceramic with additional spatial/dimensional control using the "fibrous monolith" processing approach introduced by Coblenz. ${ }^{4}$ Fibrous monoliths are sintered (or hot-pressed) monolithic ceramics with a distinct fibrous texture, consisting of intertwined cells of a primary phase, separated by cell boundaries of a tailored secondary phase. In a previous paper, ${ }^{5}$ the fabrication procedure, microstructure, indentation fracture, and preliminary mechanical properties were described for several fibrous monolithic ceramic systems. The microstructure is derived from a coated green fiber process whereby continuous green fiber containing the primary phase is coated with a slurry of the secondary phase. The coated fibers are pressed and fired, resulting in a monolithic ceramic with a fibrous microstructure.

The SiC/graphite system is an example of a weak interface fibrous monolith where the graphitic cell boundary phase acts as the preferred path for crack propagation. Weak interfaces can deflect cracks $^{6}$ or delaminate in shear, thereby increasing "toughness" and preventing brittle fracture. The high strain to failure and toughness of brittle ceramic matrices reinforced with high-strength fibers are a consequence of the weak bonding between the fibers and the matrix. 7,8

In this paper, the fracture behavior of fibrous monoliths in the $\mathrm{SiC} / \mathrm{graphite}$ system is described. The primary cell phase is

R. Ruh-contributing editor

\footnotetext{
Manuscript No. 195253. Received October 5, 1992; approved May 17, 1993.

Supported by the Defense Advanced Research Projects Agency and the Office of Naval Research under Contract No. N0014-91-J-1999.

"Member, American Ceramic Society.
}

polycrystalline $\mathrm{SiC}$. The strength of the interfacial layer is controlled by adjusting the composition of the cell boundary from $\mathrm{SiC}$ to graphite. Strength is evaluated in flexure, and damage tolerance assessed by the strength of indented bar specimens. Notched beam tests are used to estimate fracture toughness.

\section{Experimental Procedure}

Green SiC fibers were prepared by dry spinning of an ethyl methacrylate/methyl ethyl ketone polymer solution loaded with ceramic powder. The starting material was $\beta-S i C$ powder $(B 10$, Hermann C. Starck, Inc., New York, NY) without sintering aids. Yttria (Johnson Matthey Co., Ward Hill, MA) and alumina (RC-HP DBM Malakoff Industries, Malakoff, TX) were added as sintering aids. The weight ratio of SiC:yttria:alumina was 90:4:6. The volume ratio of ceramic to polymer was $55: 45$.

The graphite coating slurry was prepared by diluting an aqueous graphite slurry (Aquadag, Acheson Colloid, Port Huron, MI) containing a proprietary binder with 2 -propanol to $\approx 3$ vol\%. The silicon carbide coating slurry was prepared by milling $\mathrm{SiC}$ powder with yttria and alumina in $80 \mathrm{wt} \% 2$-propanol/ $20 \mathrm{wt} \%$ distilled water, and subsequently adding some binder (Carbowax PEG 4000, Fisher Scientific Co., Fairlawn, NJ) to decrease settling and improve the coating properties. The powder solids loading was $\approx 3$ vol\%. Coating compositions containing various amounts of $\mathrm{SiC}$ to graphite (from 20:80 to $80: 20$ ) were prepared by mixtures of the graphite slurry and the milled $\mathrm{SiC}$ slurry in the appropriate ratios. The fiber was run through the coating bath immediately upon extrusion and collected on a spool.

The coated fibers were trimmed to $\approx 51 \mathrm{~mm}$, loaded in a graphite die $(26 \mathrm{~mm} \times 52 \mathrm{~mm})$, and pressed at $\approx 80^{\circ} \mathrm{C}$ using 5 $\mathrm{MPa}$ pressure. This collapsed the fibers and consolidated the material into a green monolithic billet. After binder removal between $200^{\circ}$ and $600^{\circ} \mathrm{C}$, the billet was hot-pressed at $1900^{\circ} \mathrm{C}$ in static argon for $1 \mathrm{~h}$ at $25 \mathrm{MPa}$. Most billets were prepared with green fibers aligned in the long direction in the die. A single billet was prepared with finely chopped (lengths $<4 \mathrm{~mm}$ ) randomly oriented fibers with $100 \%$ graphite as the fiber coating. In this case, the chopped fibers were simply poured into the die and pressed. The thickness of hot-pressed billets was $\approx 4.3 \mathrm{~mm}$.

Billets with aligned fibers containing $100 \%$ graphite as the cell boundary were machined into bar specimens $4 \mathrm{~mm}$ wide and $48 \mathrm{~mm}$ long with thickness ranging from 1 to $4 \mathrm{~mm}$. All bars were machined and chamfered with a 1000-grit resinbonded diamond wheel, with the grinding direction parallel to the length of the specimen. The tensile surface was normal to the hot-pressing direction. Flexural strength was measured using a fully articulated four-point bend fixture with a $20-\mathrm{mm}$ inner span and a 40-mm outer span at a crosshead speed of 0.05 $\mathrm{mm} / \mathrm{min}$. The range in specimen thickness provided span-todepth ratios from 2.5 to 10 . The stress values were evaluated from elastic beam equations.

Five bars $(3-\mathrm{mm}$ thickness $\times 4$-mm width $\times \approx 48-\mathrm{mm}$ length) were machined from billets corresponding to each cell 
boundary composition. The tensile surface was again normal to the hot-pressing direction. Three bar specimens corresponding to each cell boundary composition were tested in the as-machined condition. The tension surfaces of the remaining two specimens from each composition were polished, indented with a 100-N load (Vickers indenter, Zwick of America, Inc., E. Windsor, CT), and tested in flexure. An identical procedure was also followed with the billet containing chopped fibers with $100 \%$ graphite as the cell boundary.

To determine the effect of texture from uniaxial hot pressing, three bar specimens $(\approx 3 \mathrm{~mm} \times 4 \mathrm{~mm} \times 48 \mathrm{~mm})$ were machined from a $\mathrm{SiC} / 100 \%$ graphite billet containing aligned fibers, such that the tensile surface was parallel to the hot-pressing direction, and then tested in flexure.

Five bar specimens $\approx 4.50 \mathrm{~mm} \times 2.25 \mathrm{~mm} \times 48 \mathrm{~mm}$ in dimension were also machined from a SiC/100\% graphite billet with aligned fibers. These specimens were notched in the center of the tensile face of the specimen with a $270-\mu \mathrm{m}$-thick diamond saw to a notch/height ratio of 0.4 (notch depth of $\approx 1.8$ $\mathrm{mm}$ ). The notch tip radius was $\approx 165 \mu \mathrm{m}$. The notched beams were tested in four-point flexure using the $20 / 40 \mathrm{~mm}$ fixture at a crosshead speed of $0.05 \mathrm{~mm} / \mathrm{min}$.

The side and tensile surfaces of some of the bar specimens used in the flexure and notch beam tests were polished with diamond paste to observe the fracture behavior optically during testing, and by scanning electron microscopy after the test. SEM was also used to characterize the fracture surfaces of the specimens.

\section{Results and Discussion}

\section{(I) Microstructure}

The microstructure of $\mathrm{SiC} /$ graphite fibrous monoliths with aligned fibers is illustrated in Fig. 1. Flattened SiC cells $60-100$ $\mu \mathrm{m}$ thick and 150-200 $\mu \mathrm{m}$ wide are separated by thin cell boundaries. The cross section in Fig. 1(C) shows cells varying in length from about $200 \mu \mathrm{m}$ to several millimeters in the long direction of the billet. Although long green fibers are placed in the die, the forming procedure can result in finite cell lengths. Green fibers can fracture or bend, and also may not lie perfectly normal to the pressing direction or perfectly parallel to the long die wall. The graphite cell boundaries vary in thickness from 1 to $10 \mu \mathrm{m}$, indicating some nonuniformity in fiber coating.

The total graphite content of the $\mathrm{SiC} / 100 \%$ graphite fibrous monolith was $4 \mathrm{wt} \%$, as determined by weight loss after 10 -h oxidation at $800^{\circ} \mathrm{C}$ in air. Thermogravimetric analysis showed that weight loss was complete after $1 \mathrm{~h}$ at $700^{\circ} \mathrm{C}$. After oxidation of the cell boundaries, the sample was essentially loosely bonded $\mathrm{SiC}$ cells which could be crushed by hand. The density of the $\mathrm{SiC} / 100 \%$ graphite fibrous monolith was $3.07 \mathrm{~g} / \mathrm{cm}^{3}$, as measured by the Archimedes method. There was negligible open porosity. The polycrystalline $\mathrm{SiC}$ cells were seen to be pore-free by SEM. We can infer the density of the cells by comparison to the $\mathrm{SiC} / 0 \%$ graphite fibrous monolith (i.e., hotpressed $\mathrm{SiC}$ with yttria and alumina), which was $3.20 \mathrm{~g} / \mathrm{cm}^{3}$. By combining this information, we infer that the polycrystalline cells occupied $\approx 92 \mathrm{vol} \%$, with the cell boundaries occupying $\approx 8 \mathrm{vol} \%$. The cell boundaries themselves were porous, consisting of $\approx 70 \mathrm{vol} \%$ graphite and $\approx 30$ vol\% porosity. The cell phase was $\beta$-SiC, as determined by $\mathrm{X}$-ray diffraction.

\section{(2) Flexural Strength Behavior of SiC/100\% Graphite}

The load-deflection curve for a $\mathrm{SiC} / 100 \%$ graphite flexure specimen of dimensions $3 \mathrm{~mm} \times 4 \mathrm{~mm} \times 48 \mathrm{~mm}$, machined with the tension side ( $4 \mathrm{~mm}$ wide) normal to the pressing direction, is shown in Fig. 2(A). The apparent tensile stress on the surface increased linearly to a maximum value, followed by a gradual load decrease. The maximum flexural stress on the tension side was $215 \mathrm{MPa}$. Load drops were accompanied by shear cracking along the midplane of the specimen between the inner and outer loading points. Examination of the specimen after several load drops after deflection of $\approx 150 \mu \mathrm{m}$ showed that the shear crack had extended along cell boundaries from the inner loading point to the edge of the specimen. The beam after unloading did not show any curvature or permanent strain. Reloading the specimen showed that the compliance of the specimen had increased. Further crosshead displacement resulted in extensive delaminations, and ultimately cracking below the inner loading point through the thickness of the beam. The side surface of the bent specimen is shown in Fig. 2(B).

The flexural behavior depends upon specimen thickness. For example, the load-deflection curve for a $\mathrm{SiC} / 100 \%$ graphite specimen with a thickness of $1.2 \mathrm{~mm}$ is shown in Fig. 3. The maximum flexural stress was $322 \mathrm{MPa}$. Again, a linear increase in stress to the maximum value was followed by a gradual load decrease. Examination of specimens after testing showed that fracture originated at or near the tensile surface between the inner loading points, but was then followed by shear fracture almost parallel to the surface along the graphite cell boundaries. The splintered fracture morphology is illustrated in SEM photomicrographs of the side and tensile surfaces of a specimen after test (Figs. 4(A) and (B)). Fracture cells are visible on the tension side.

The fracture behavior in flexure is consistent with the change in ratio of the shear to tensile stress with decreasing thickness. For elastic beam conditions, the ratio $(\sigma / \tau)$ of tensile stress on the surface to shear stress in the midplane between the inner and outer loading points is equal to $2(L-l) / t$ where $L$ and $l$ are the inner and outer spans of the bend fixture and $t$ is the thickness of the specimen. ${ }^{9,10}(L-l) / 2$ is the separation distance between the inner and outer loading points. At low span-to-depth ratios $((L-l) / 2 t<5)$, failure occurs when the shear stress reaches a critical value, and in this regime, maximum "flexural strength" should increase linearly with the inverse of thickness. The effect of specimen thickness on apparent flexural strength is shown in Fig. 5. The slope of the best-fit line through the data points at low span-to-depth ratios is proportional to the shear strength. The calculated shear strength of the graphite cell boundaries normal to the pressing direction is $15 \mathrm{MPa}$. This estimate of the shear strength falls within the range of peak shear strength values reported for carbon-rich interfacial layers in tough fiber-reinforced ceramics. ${ }^{8}$ At high span-to-depth ratios $((L-l) / 2 t \geq 8)$, fracture initiates at the tension side, and the maximum flexural stress is not a function of thickness. The average flexural strength is $339 \mathrm{MPa}$.

The fracture behavior at low span-to-thickness ratios in this fibrous monolithic system is identical to the shear failure observed in ceramic matrices reinforced by high-strength fibers with short beam geometry. ${ }^{10}$ But at high span-to-depth ratios, the material fails like wood, ${ }^{11}$ with fracture behavior very similar to SiC-fiber-reinforced glass ceramic at high temperatures where higher interfacial shear strength decreases fiber pullout. ${ }^{12}$

\section{(3) Effect of Cell Boundary Composition}

The low shear strength of the graphite cell boundaries promotes delamination resulting in noncatastrophic failure. The shear strength of the cell boundaries can be increased by adding $\mathrm{SiC}$ (with yttria and alumina) to the graphite in the fiber coating. The effect of cell boundary composition on average flexural strength of SiC-based fibrous monoliths is shown in Fig. 6(A). The apparent work-of-fracture calculated from the area under the load-deflection curve and the specimen cross-sectional area is plotted in Fig. 6(B) as a function of cell boundary composition.

The mean flexural strength corresponding to the $100 \%$ graphite cell boundary was $216 \mathrm{MPa}$, with strengths ranging from 210 to $221 \mathrm{MPa}$. The actual value is not meaningful for this composition since failure for the sample dimensions used in this experiment is dictated only by the shear strength of the cell boundary. However, the value is useful for comparison with the average strength of indented samples which was almost $90 \%$ of the unindented strength. Indentation simply results in spalling 


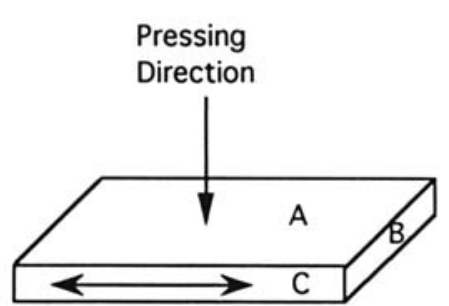

Fiber Alignment

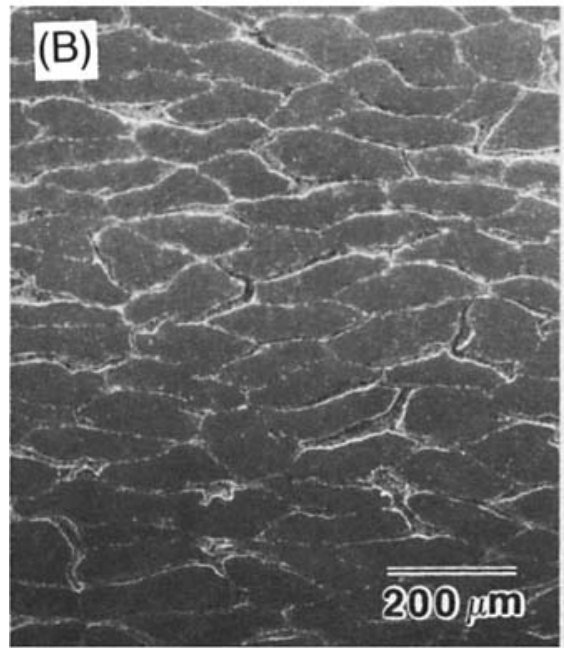

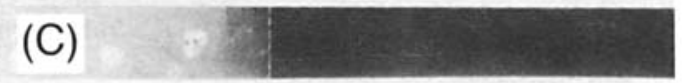

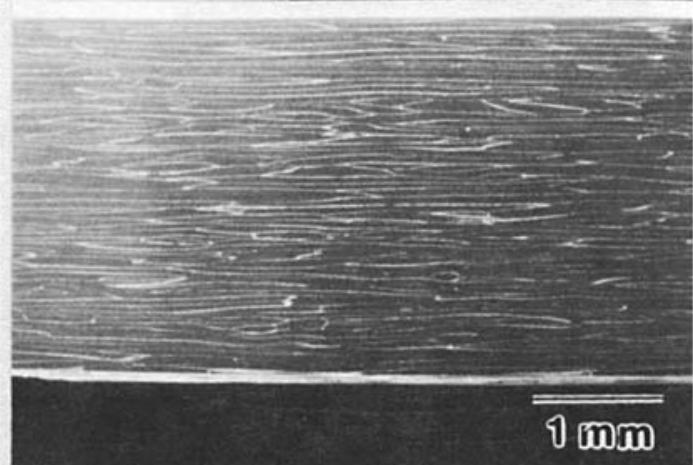

Fig. 1. Microstructure of SiC/graphite fibrous monolith prepared with aligned green fibers. The graphite cell boundaries appear bright in the SEM micrographs.

of cells, and extrusion of graphite from the cell boundaries. ${ }^{5}$ Failure does not occur from the indentation, but from shear cracking. As the flexural stress is not indentation sensitive, this cell/cell-boundary combination is considered damage tolerant.

As noted earlier, the samples with $100 \%$ graphite at the cell boundaries display graceful failure, and the apparent work-offracture is $\approx 1300 \mathrm{~J} / \mathrm{m}^{2}$, which is substantially higher than the work-of-fracture of $<100 \mathrm{~J} / \mathrm{m}^{2}$ expected for polycrystalline $\mathrm{SiC}$ toughened with additions of yttria and alumina. ${ }^{13}$ The calculated work-of-fracture will vary with specimen thickness and loading configuration, ${ }^{10}$ but is used here for comparison with other compositions for the same thickness.

A bar specimen with cell boundries of $100 \%$ graphite was pulled apart by hand after the test. The fracture surface is shown in Fig. 7(A). The terraced topography in the tensile half of the specimen shows the preferential crack growth along the graphite cell boundaries which appear bright in the SEM micrograph.

Samples with cell boundaries containing 80 vol\% graphite/ $20 \mathrm{vol} \% \mathrm{SiC}$ behaved in a similar manner, with graceful failure, and slightly higher average strength $(234 \mathrm{MPa})$ and also very little decrease in strength on indentation. Failure again occurred by shear cracking, with the higher flexural strength implying a slight increase in the cell boundary shear strength over that of pure graphite. The apparent work-of-fracture was correspondingly lower at $\approx 1000 \mathrm{~J} / \mathrm{m}^{2}$. The surface of a fractured specimen is also terraced as shown in Fig. 7(B).

When the graphite content in the cell boundary was decreased to $60 \mathrm{vol} \%(40 \mathrm{vol} \% \mathrm{SiC})$, failure occurred in a brittle manner with the load dropping to zero. The average flexural strength of the three samples was $\approx 355 \mathrm{MPa}$. Two of the three samples with the higher strengths broke in two, but the third specimen with the lowest strength remained intact with some load-bearing ability. The SEM photomicrograph in Fig. 8 of the side surface of this specimen shows the fracture originating on the tension side, with shear fracture occurring beyond the neutral plane. The fracture surface of a broken specimen in Fig. 7(C) shows considerable topography, but noticeably less than samples containing $80 \%$ and $100 \%$ graphite at the cell boundaries. The indented strength was lower $(285 \mathrm{MPa})$ but was still $80 \%$ of the unindented strength, indicating considerable damage tolerance. The work-of-fracture is assumed to be close to that of polycrystalline $\mathrm{SiC}$.

With only 40 vol\% graphite in the cell boundary, the bars were brittle but with slightly higher average strength of 383 $\mathrm{MPa}$. The fracture surface of the specimen in Fig. 7(D) is much smoother, with some evidence of stepped fracture at cell boundaries. The indented strength was $80 \%$ of the original strength. Cell boundaries with only $40 \%$ graphite appear to be effective in limiting indentation damage and making the sample flaw tolerant. It is useful to point out here that although a statistically small sample of two bars was indented for each composition, the two values did not differ by more than $3 \%$ for compositions containing greater than $20 \mathrm{vol} \%$ graphite.

When the cell boundary composition is 20 vol\% graphite/80 vol\% $\mathrm{SiC}$, strength is much higher (average $\sigma=480 \mathrm{MPa}$, with strengths ranging from 438 to $532 \mathrm{MPa}$ ), and fracture is brittle and relatively featureless near the tensile surface (see Fig. $7(\mathrm{E})$ ). Shear lips at the cell boundaries are evident only from the neutral axis about $1.5 \mathrm{~mm}$ from the top edge. The average indented strength is only $\approx 50 \%$ of the average unindented strength. The strength loss is significant but still better than polycrystalline $\mathrm{SiC}$.

With $100 \% \mathrm{SiC}$ (no graphite) at the cell boundary, the material is simply polycrystalline SiC densified with yttria and alumina, with no remnant texture from the green fibers. Average four-point bend strength is $640 \mathrm{MPa}$ (with strengths ranging from 566 to $704 \mathrm{MPa}$ ), with brittle fracture and poor flaw tolerance. The indented strength values were.162 and $175 \mathrm{MPa}$. The 

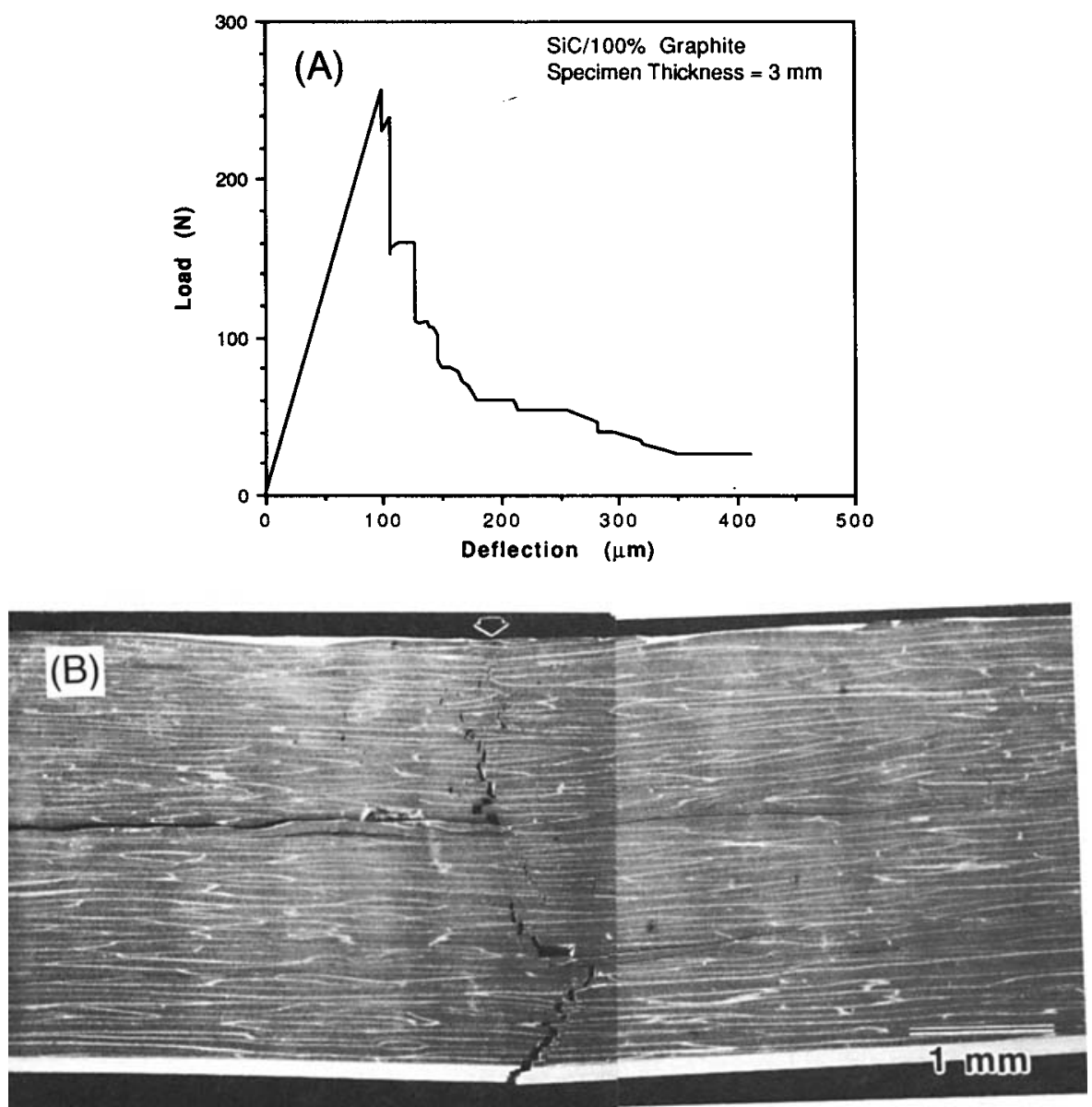

Fig. 2. (A) Load-deflection curve for SiC/graphite flexure specimen of 3-mm thickness. (B) Side surface of bent specimen after test; inner loading point indicated by arrow, outer loading point outside and to the left of field of view.

unindented specimens broke into several pieces on testing, and no fractography was done.

\section{(4) Effect of Anisotropy and Fiber Alignment}

It is evident from the micrographs in Fig. 1 that significant texture is present in these billets due to the forming process. The cross section of a billet normal to the fiber direction consists of flattened cells with graphite cell boundaries. The flexural strength behavior presented in Section III(2) has

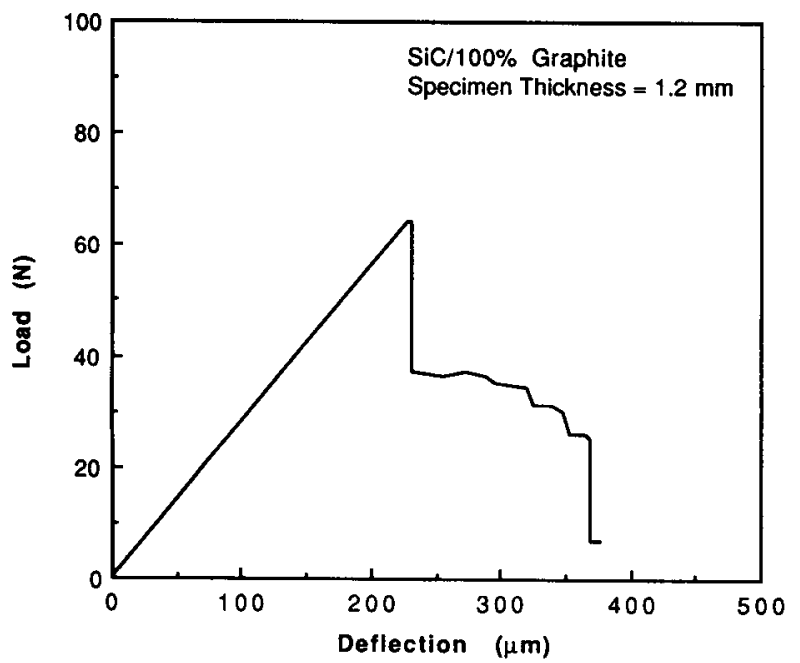

Fig. 3. Load-deflection curve for $\mathrm{SiC} /$ graphite flexure specimen with thickness of $1.2 \mathrm{~mm}$. demonstrated that graphite cell boundaries normal to the pressing direction are weak, resulting in shear failure for low (3 to 5) span-to-depth ratios.

The fracture behavior is markedly different for bar specimens machined in the transverse direction with the tension side parallel to the pressing direction, and tested at a low (3.3) span-todepth ratio. The average strength of three bars was $303 \mathrm{MPa}$, with strengths ranging from 283 to $313 \mathrm{MPa}$. A linear increase to the maximum stress value was followed by a significant load drop. The specimens remained intact with some load-bearing ability. Failure originated at the tensile surface. Good agreement is observed between the measured strength of 303 $\mathrm{MPa}$ and the flexural strength of the bars at high span-to-depth ratios shown in Fig. 5.

The specimens machined in the transverse direction do not fail by midplane shear cracking as was expected at low span-todepth ratios. There are two possible reasons for this fracture behavior. It is possible that hot pressing results in crystallographic orientation of graphite particles in cell boundaries which facilitates shear delamination normal to the pressing direction but not along the planes defined by the cell axis and the pressing direction. But, more likely, the inherent texture and layout of the cell boundaries lead to differences in the propensity for shear fracture between the two orientations. A much greater percentage of cell boundary segments lie normal to rather than parallel with the pressing direction, causing shear cracking only when the specimen neutral plane is normal to the pressing direction.

The strength and fracture behavior of $\mathrm{SiC} /$ graphite fibrous monoliths is also influenced by the method of green fiber layup in the die. The data presented so far were obtained with fibers aligned in the long direction of the billet. The microstructure 

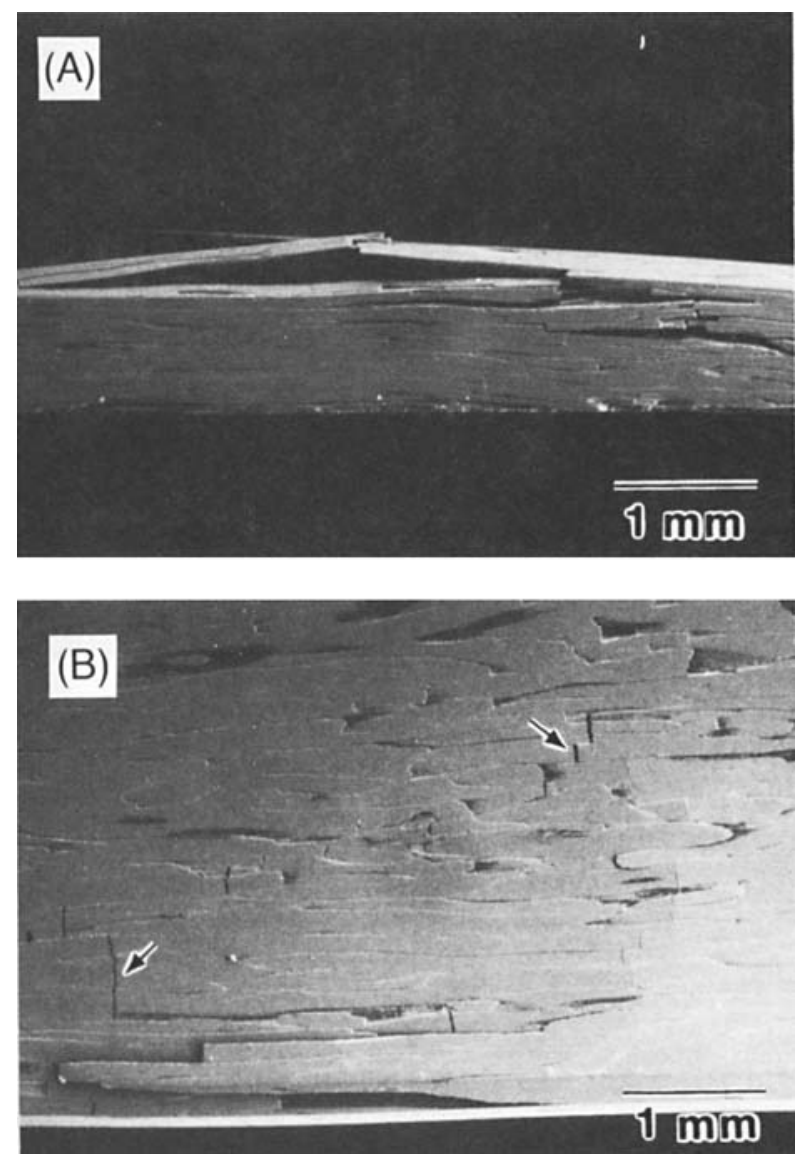

Fig. 4. SEM micrographs of side (A) and tensile (B) surfaces of thin $\mathrm{SiC} /$ graphite flexure specimen after test. Fractured cells on the tensile surface are indicated by arrows.

and fracture behavior are significantly different when the preform is made from randomly oriented green chopped fibers. This die-filling procedure is easier than aligning fibers, as it simply involves pouring the chopped fibers into the die. The side surface of a bar specimen with chopped fibers after testing is shown in Fig. 9(A). Fracture initiates at the tensile surface,

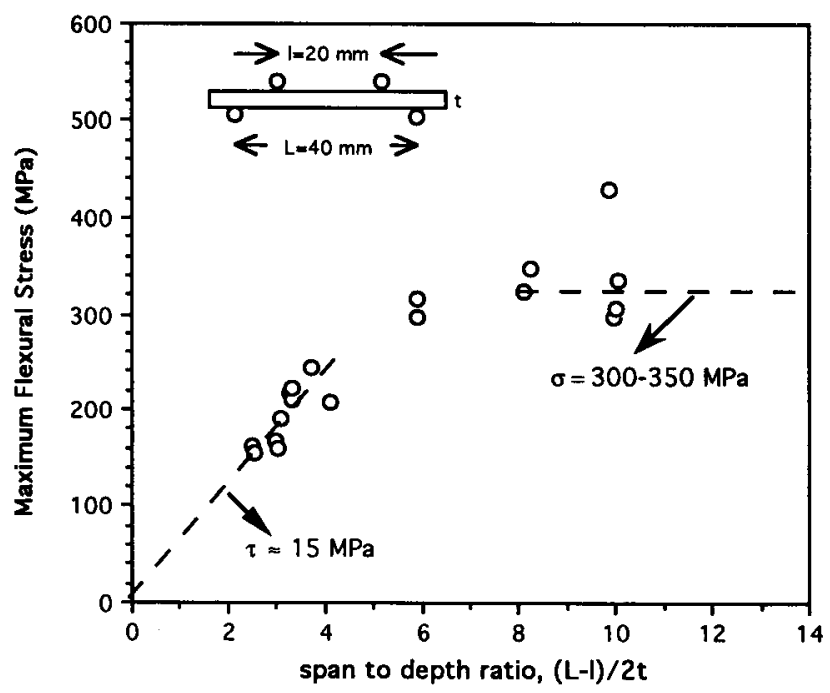

Fig. 5. Apparent flexural strength as a function of span to depth ratio for SiC/graphite.
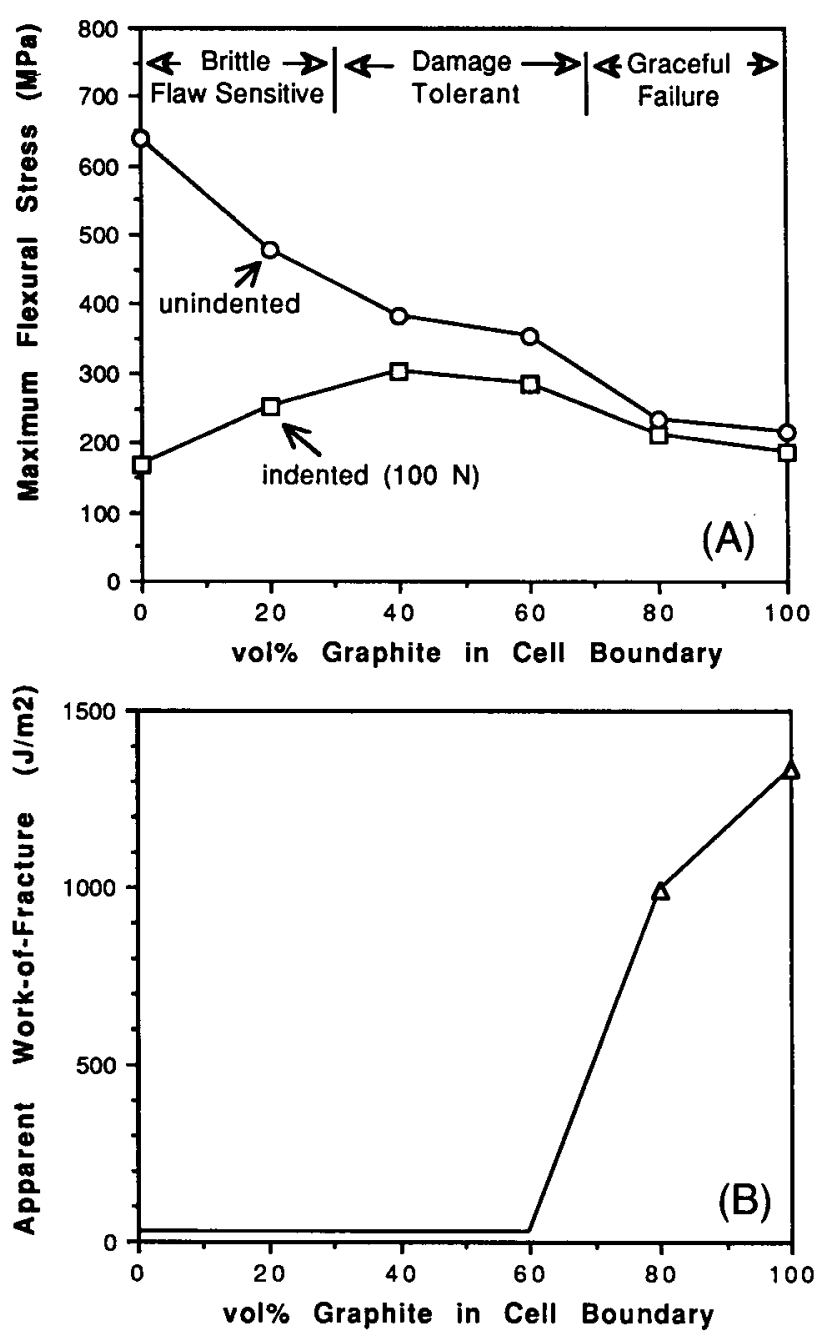

Fig. 6. Effect of cell boundary composition on (A) maximum flexural stress and (B) apparent work of fracture of SiC-based fibrous monoliths.

followed by crack propagation mostly along the cell boundaries. Average flexural strength for both unindented and indented specimens was $123 \mathrm{MPa}$. Strengths of unindented samples ranged from 122 to $125 \mathrm{MPa}$. The randomly oriented cell architecture results in some cells (and, therefore, cell boundaries) being oriented normal to the applied stress. This causes failure initiation at the weak cell boundaries on the tension side as shown in Fig. 9(B), which results in low strengths. The strength simply corresponds to the low off-axis strength expected in a billet with aligned fibers. Cracks do not initiate from indentations ${ }^{5}$ and so strength remains the same after indentation.

\section{(5) Notched-Beam Testing of SiC/100\% Graphite}

The load-deflection behavior of a notched beam of the $\mathrm{SiC} /$ $100 \%$ graphite fibrous monolith tested in four-point flexure is shown in Fig. 10(A). The load increases linearly to $\approx 52 \mathrm{~N}$ followed by a nonlinear increase to the maximum load of $125 \mathrm{~N}$. Observation of the side surface of a notched specimen during the test did not show evidence of cracks at the first sign of nonlinearity. But it is quite possible damage begins to occur along cell boundaries in the interior of the sample. With increasing load, delamination cracks were observed to nucleate and grow axially from the tip of the notch on the surface. The side surface of a notched specimen after the test is shown in Fig. 10(B). Delamination cracking has occurred through the thickness of the specimen ahead of the notch, with stepped fracture through 

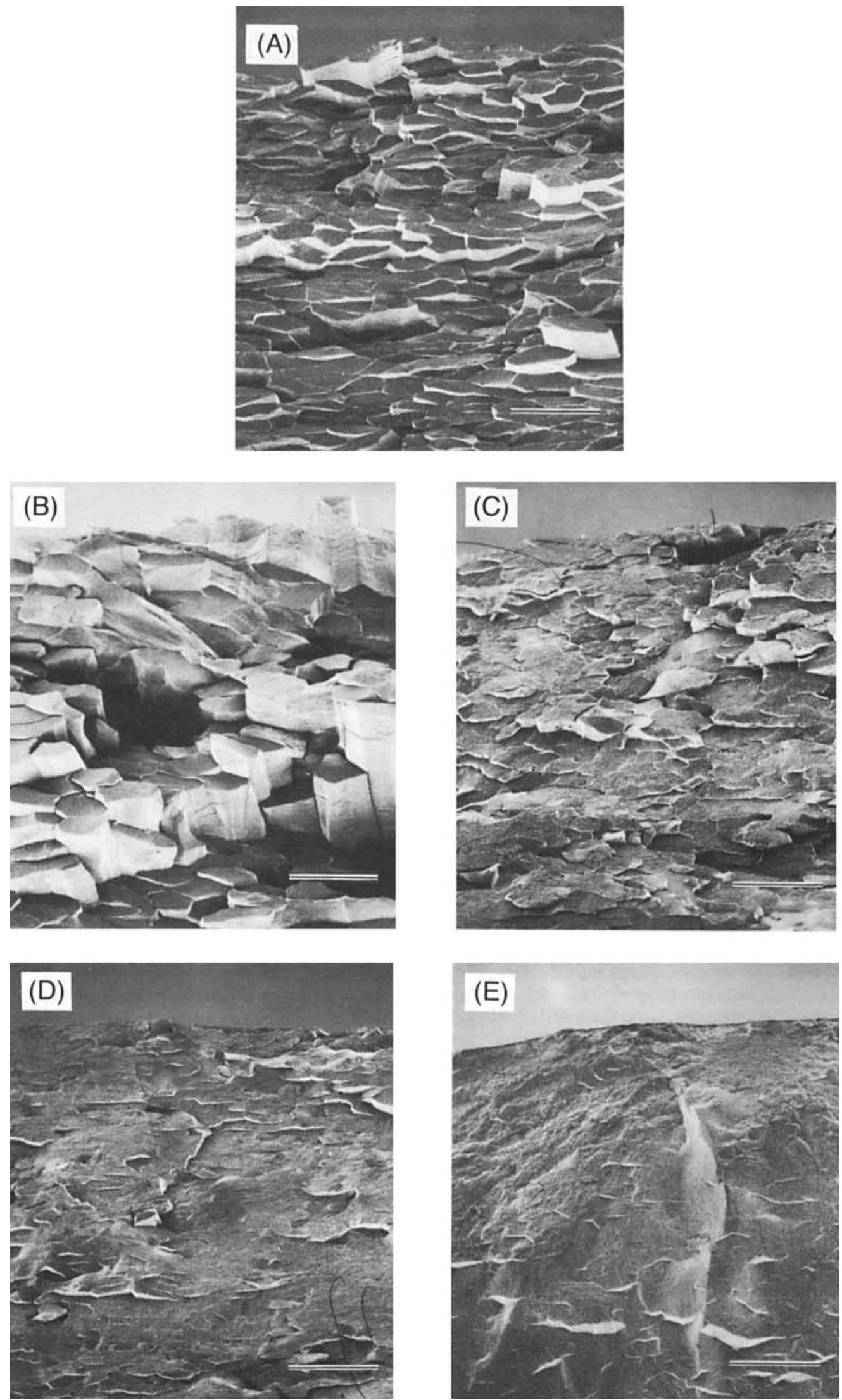

Fig. 7. Fracture surfaces of SiC-based fibrous monoliths with cell boundaries containing (A) $100 \%$, (B) $80 \%$, (C) $60 \%$, (D) $40 \%$, and (E) 20 vol\% graphite. 


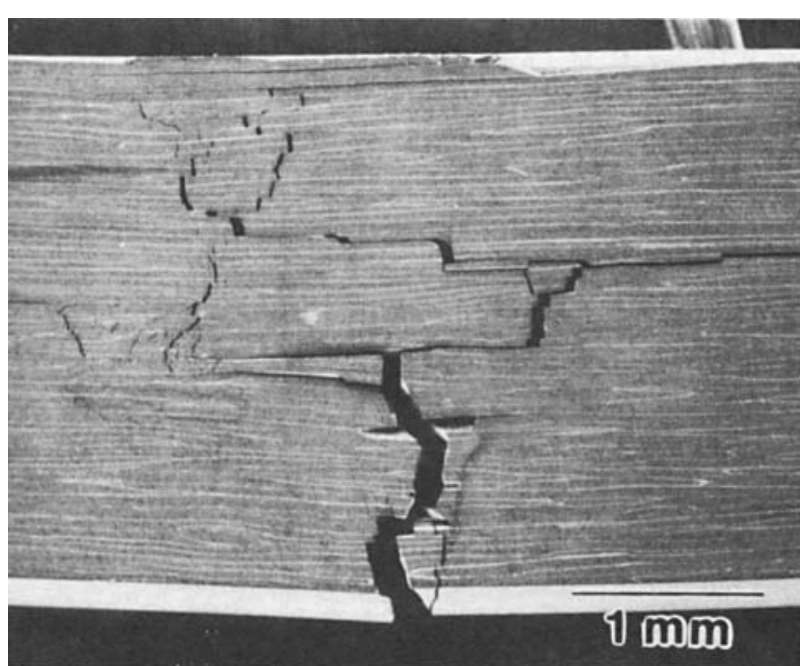

Fig. 8. SEM micrograph of side surface of flexure specimen of $\mathrm{SiC} /$ 60 vol\% graphite. Fracture initiates on the tension side at the bottom.

cells connecting the delamination cracks. Fracture behavior from the notch is similar to the delamination cracking observed in notch-insensitive materials like wood ${ }^{11}$ and ceramic composites reinforced with high-strength continuous fibers. ${ }^{7,10,14}$ Since extension of a crack in a direction normal to the applied stress
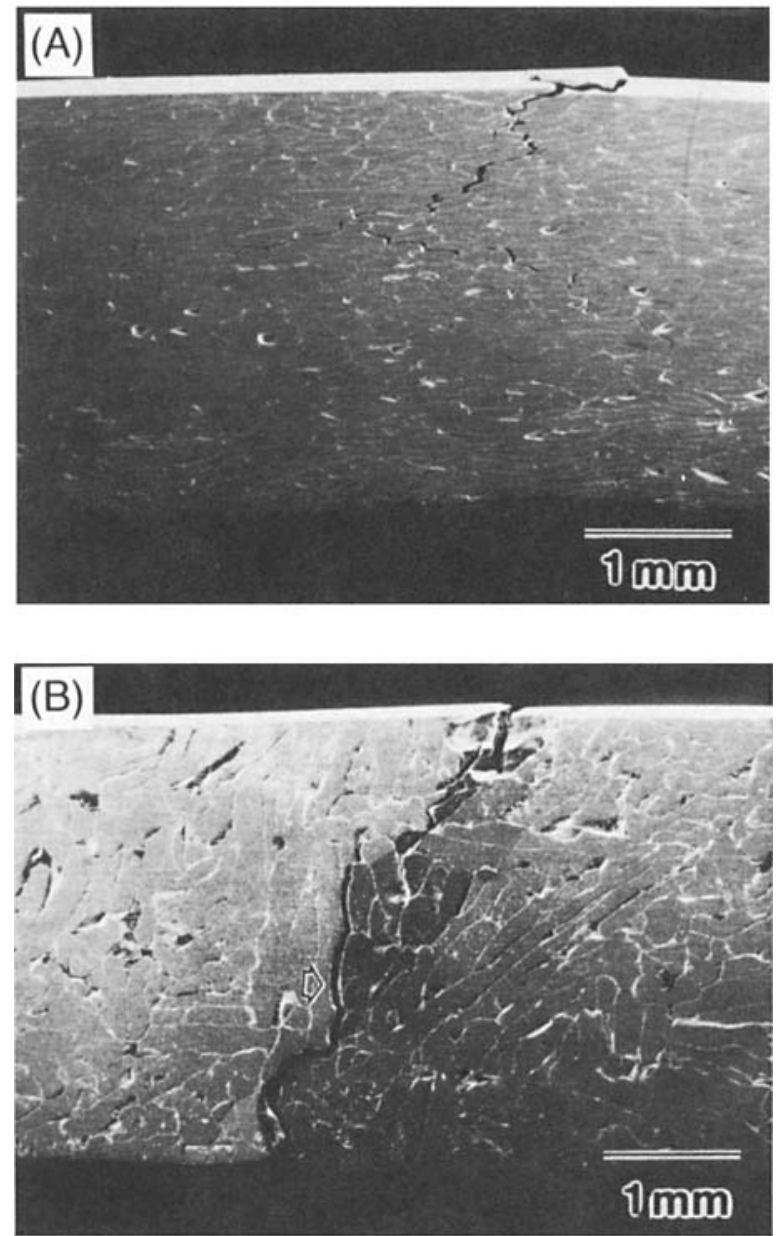

Fig. 9. SEM micrographs showing side (A) and tensile (B) surfaces of flexure specimens of $\mathrm{SiC} / 100 \%$ graphite prepared with randomly oriented chopped fibers. Arrow indicates graphite cell boundary normal to applied stress direction on the tensile surface. does not occur, it is not possible to obtain a Mode I fracture toughness.

\section{Conclusion}

High work-of-fracture, flaw tolerance, and "graceful failure" can be obtained in monolithic $\mathrm{SiC}$ with the fibrous monolith design. The flexural strength and fracture behavior in the $\mathrm{SiC} /$ graphite system depend on a wide range of parameters. Depending on the loading configuration, materials can fail by shear cracking or from the tensile surface. The interfacial strength significantly affects the strength, damage tolerance, and type of failure. Variations in cell boundary composition alter the fracture morphology. Texture and fiber orientation also influence the fracture behavior. Low-strength cell boundaries cause the material to be notch insenstive and prevent extension of cracks normal to the applied stress. This microstructural arrangement shows useful properties which could possibly be improved.

The fibrous monolith microstructure design using weak cell boundaries are in some ways similar to continuous-fiberreinforced ceramics ${ }^{7,12}$ and weak-interface laminates. ${ }^{2}$ The microstructural units are polycrystalline cells which are derived from the fiber material, with the cell boundaries derived from
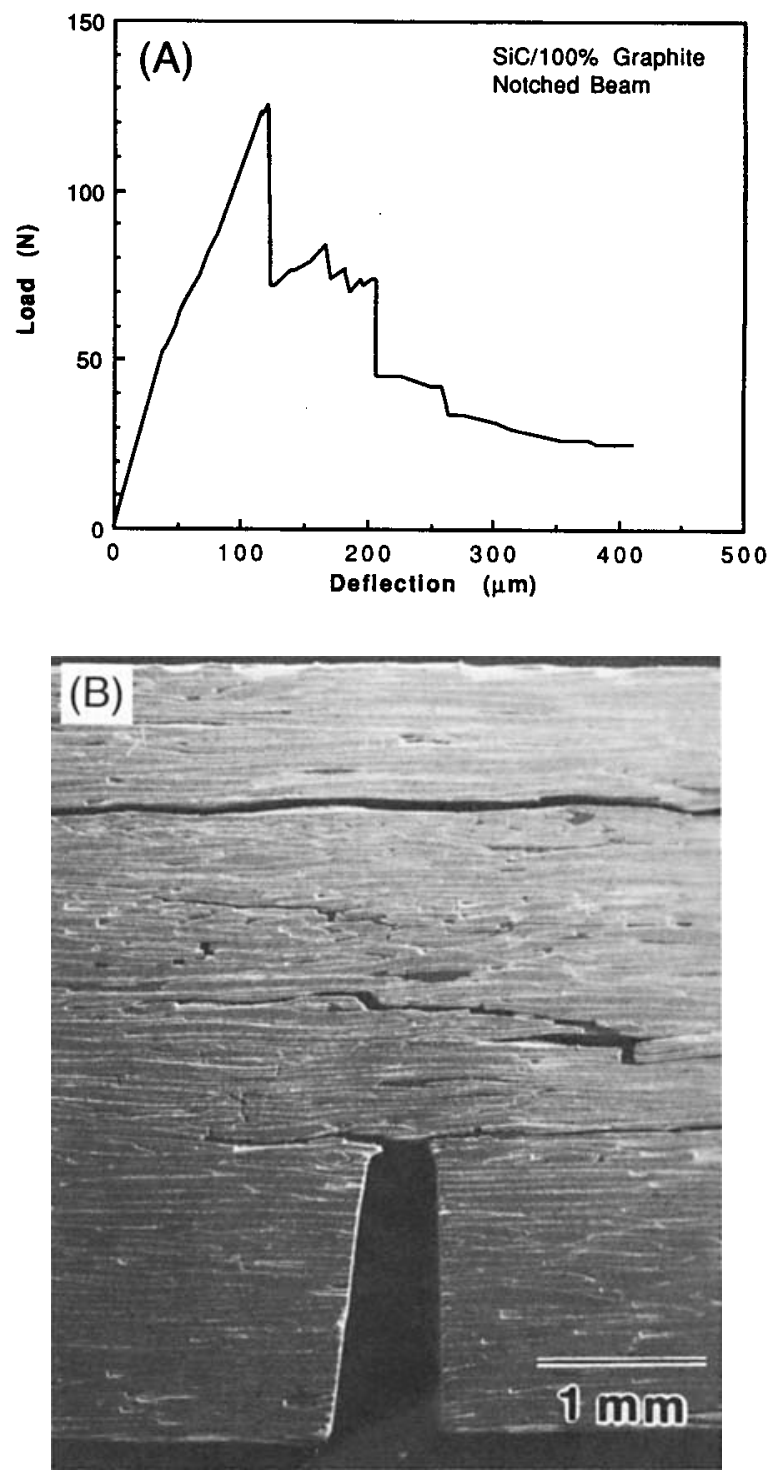

Fig. 10. (A) Load-deflection curve for a notched beam of $\mathrm{SiC} / 100 \%$ graphite tested in flexure. (B) Side surface showing delamination cracking in the notched beam. 
the fiber coating material. Each cell is not straight and continuous in the axial direction unlike the fibers in ceramic-matrix composites. The cell lengths can be very short when chopped fibers are used. The cells also do not have planar continuity normal to the pressing direction unlike laminates. The cells are however flattened in the pressing direction, resulting in some texture, and orientation effects on the shear properties. The weak-interface fibrous monolith can be best compared with geological rock fabrics consisting of lensoid microlithons with reticulate cleavage. ${ }^{15}$

The mechanical properties show important differences with fiber-reinforced ceramics and laminates. The weak interface fibrous monoliths show linear load-deflection behavior prior to the maximum load. Strain-to-failure at maximum strength is, therefore, low. Strength is lower than the reported value of 630 MPa for SiC/graphite laminates, ${ }^{2}$ and the ultimate strengths of fiber-reinforced ceramics. ${ }^{72}$ But the fibrous monoliths are damage tolerant, notch insensitive, and characterized by noncatastrophic fracture behavior.

For the $\mathrm{SiC} / 100 \%$ graphite system, flexural strength is 300 $350 \mathrm{MPa}$, and the shear strength normal to the pressing direction is $15 \mathrm{MPa}$. Combinations of alternative cell materials (of compatible polycrystalline structural ceramics) and weak cell boundaries (e.g., boron nitride) have the potential for yielding weak-interface fibrous monoliths with higher strength, adequate toughness, and damage tolerance.

Acknowledgment: Experimental assistance in fiber spinning was provided by Tim Fretter.

\section{References}

'M. P. Harmer, H. M. Chan, and G. A. Miller, "Unique Opportunities for Microstructural Engineering with Duplex and Laminar Ceramic Composites," J. Am. Ceram. Soc., 75 [7] 1715-28 (1992).

${ }^{2}$ W. J. Clegg, K. Kendall, N. McN. Alford, T. W. Button, and J. D. Birchall, "A Simple Way to Make Tough Ceramics," Nature (London), 347, 455-57 (1990).

${ }^{3}$ C. A. Folsom, F. W. Zok, and F. F. Lange, "Flexural Properties of Brittle Matrix Laminar Composites," Ceram. Eng. Sci. Proc., 13 [7-8] 469-74 (1992).

${ }^{4}$ W. S. Coblenz, "Fibrous Monolithic Ceramic and Method for Production," U.S. Pat. No. 4772524 , September 20, 1988.

${ }^{5}$ S. Baskaran, S. D. Nunn, D. Popovic, and J. W. Halloran, "Fibrous Monolithic Ceramics: I, Fabrication, Microstructure, and Indentation Behavior," J. Am. Ceram. Soc., 76 [9] 2209-16 (1993).

${ }^{6} \mathrm{~J}$. Cook and J. E. Gordon, "A Mechanism for the Control of Crack Propagation in All-Brittle Systems," Proc. R. Soc. London, A282, 508-20 (1964).

${ }^{7} \mathrm{~K}$. M. Prewo and J. J. Brennan, "High-Strength Silicon Carbide Fiber-Reinforced Glass-Matrix Composites,"J. Mater. Sci., 15, 463-68 (1980).

${ }^{8}$ R. J. Kerans, R. S. Hay, N. J. Pagano, and T. A. Parthasarathy, "The Role of the Fiber-Matrix Interface in Ceramic Composites," Am. Ceram. Soc. Bull., 68 [2] 429-42 (1989).

${ }^{9}$ R. J. Roark, Formulas for Stress and Strain, 4th ed.; Ch. 8. McGraw-Hill, New York, 1965 .

'D. B. Marshall and A. G. Evans, "Failure Mechanisms in Ceramic-Fiber/ Ceramic-Matrix Composites," J. Am. Ceram. Soc., 68 [5] 225-31 (1985).

"M. F. Ashby, K. E. Easterling, R. Harrysson, and S. K. Maiti, "The Fracture and Toughness of Woods," Proc. R. Soc. London, A, 398, 261-80 (1985).

${ }^{12} \mathrm{~K}$. M. Prewo, "Tension and Flexural Strength of Silicon Carbide Fiber-Reinfoced Glass Ceramics," J. Mater. Sci., 21, 3590-600 (1986).

${ }^{13}$ K. Y. Chia and C. K. Lau, "High Toughness Silicon Carbide," Ceram. Eng. Sci.Proc., 12 [9-10] 1845-61 (1991).

${ }^{14}$ O. Sbaizero, P. G. Charalambides, and A. G. Evans, "Delamination Cracking in a Laminated Ceramic-Matrix Composite," J. Am. Ceram. Soc., 73 [7] 193640 (1990).

${ }^{15} \mathrm{G}$. J. Borradaile, M. B. Bayly, and C. M. Powell, Atlas of Deformational and Metamorphic Rock Fabrics; p. 2. Springer-Verlag, New York, 1982. 